\title{
Gadolinium and nephrogenic systemic fibrosis: an update
}

\author{
Alex Weller • Joy L Barber • Øystein E Olsen
}

Received: 3 June 2013 /Revised: 28 August 2013 / Accepted: 9 September 2013 / Published online: 22 October 2013

(C) IPNA 2013

\begin{abstract}
Nephrogenic systemic fibrosis (NSF) is a multisystem disease seen exclusively in patients with renal impairment. It can be severely debilitating and sometimes fatal. There is a strong association with gadolinium-based contrast agents used in magnetic resonance imaging (MRI). Risk factors include renal impairment and proinflammatory conditions, e.g. major surgery and vascular events. Although there is no single effective treatment for NSF, the most successful outcomes are seen following restoration of renal function, either following recovery from acute kidney injury or following renal transplantation. There have been ten biopsy-proved pediatric cases of NSF, with no convincing evidence that children have a significantly altered risk compared with the adult population. After implementation of guidelines restricting the use of gadolinium-based contrast agents in at-risk patients, there has been a sharp reduction in new cases and no new reports in children. Continued vigilance is recommended: screening for renal impairment, use of more stable gadolinium chelates, consideration of non-contrast-enhanced MRI or alternative imaging modalities where appropriate.
\end{abstract}

Keywords Nephrogenic systemic fibrosis $\cdot$ Nephrogenic fibrosing dermopathy $\cdot$ Magnetic resonance imaging . Gadolinium · Contrast agents $\cdot$ Kidney disease $\cdot$ End-stage renal disease $\cdot$ Children

\section{Introduction}

Nephrogenic systemic fibrosis (NSF) is a multisystem fibrosing condition observed in patients with renal impairment

\footnotetext{
A. Weller $(\bowtie) \cdot$ J. L. Barber

Department of Radiology, St George's Hospital NHS Trust, Blackshaw Road, London SW17 0QT, UK

e-mail: alweller@gmail.com

Ø. E. Olsen

Radiology Department, Great Ormond Street for Children NHS

Foundation Trust, Great Ormond Street, London WC1N 3JH, UK
}

[1]. It causes morbidity through systemic fibrosis, including skin fibrosis and associated joint contractures. The occurrence of NSF following gadolinium (Gd)-based contrast-agent administration was first reported in 2006 [2]. These agents are used in magnetic resonance imaging (MRI) to improve diagnostic efficacy. Their use is widespread, with millions of examinations performed annually. NSF has been reported in approximately 500 patients worldwide, but in dialysis patients given high doses of $\mathrm{Gd}$, the incidence is as high as $18 \%$ [3]. Only ten biopsy-proven cases in children have been reported [4]. We will discuss the emergence of NSF as a clinical entity and consider the evidence for $\mathrm{Gd}$ as a causative agent. This includes a review of the impact of international guidelines restricting the use of Gd on the incidence of NSF since 2006 and an overview of alternative and adapted imaging techniques available for children with renal impairment.

\section{NSF as a distinct clinicopathological entity}

Cowper et al., in 2000, were the first authors to describe nephrogenic fibrosing dermopathy as a distinct clinical entity in a series of 15 patients [1]. These cases had either received or were receiving renal dialysis and presented with thickening and hardening of the skin with brawny hyperpigmentation in a typically symmetrical distribution, most commonly affecting the extremities from ankles to midthighs and from wrists to midupper arms. Deep-skin biopsy showed extensive fibrosis that was different histologically from clinically similar entities.

The term nephrogenic systemic fibrosis (NSF) emerged following reports of systemic involvement seen at autopsy, including a report of respiratory failure following extensive phrenic fibrosis [5, 6]. Myopathy and polyneuropathy have also been demonstrated [7]. However, due to the high level of comorbidity in this patient group, there may be some overlap with systemic fibrosis due to other causes, such as uremic cardiomyopathy or uremic pleurisy $[8,9]$. NSF has no single diagnostic, clinical or histologic feature. The clinical picture in NSF is very similar to scleromyxedema, but NSF favors the extremities and trunk 
rather than the head and neck [10]. Other differentials such as morphea differ both clinically and histologically) [11]. Deepskin biopsy that includes the fascia is essential for diagnosis. Early histological descriptions were of dermal spindle-cell proliferation and disorganized, thickened collagen bundles separated by clefts and with variable quantities of mucin and elastic fibers. Differentiating features from similar clinical entities includes dual positivity of fibrocytes for CD34 and procollagen 1, although this can be seen in other fibrosing lesions such as scleroderma [12]. Additionally, rather than deriving from dermal dendrocytes, the dominant cell in dermal biopsies in NSF has a similar immunohistochemical fingerprint to bone-marrowderived circulating fibrocytes [13]. Osseous metaplasia with disorganized fragments of bone may also be seen on skin biopsy in NSF. This finding appears to be relatively specific, although its significance is unclear [14] Following are differential diagnoses for NSF in adults and children:

- Scleromyxedema

- Lipodermatosclerosis

- Eosinophilia-myalgia syndrome

- Eosinophilic fasciitis (Schulman syndrome)

- Systemic sclerosis/morphea

- Porphyria cutanea tarda

- Fibroblastic rheumatism

- Scleredema

- $\beta_{2}$ microglobulin amyloidosis

- Dermatofibrosarcoma protuberans

The International Center for Nephrogenic Systemic Fibrosis Research (ICNSFR) is a collaborative research group based at Yale University, New Haven, CT, USA. A component of this is the NSF Registry, a database of biopsyconfirmed cases of NSF. In 2009 the organization proposed a clinicopathological scoring system derived from published literature and registry data aimed at achieving diagnostic standardization (Tables 1, 2 and 3 and Fig. 1) [15].

\section{How serious a problem is NSF?}

More than 500 cases of NSF have been reported to MedWatch, the US Food and Drugs Administration (FDA) database [16]. However, as MedWatch does not require histopathological

Table 1 Proposed criteria for the diagnosis of nephrogenic systemic fibrosis (NSF): clinical features

\begin{tabular}{ll}
\hline Major clinical criteria & Minor clinical criteria \\
\hline Patterned plaques & Puckering/linear banding \\
Joint contractures & Superficial NSF (plaque/patch) \\
Cobblestoning & Dermal papules \\
Marked induration/peau d'orange & Scleral Plaques (pt $<45 \mathrm{yo})$ \\
\hline
\end{tabular}

Table 2 Proposed histological criteria for the diagnosis of nephrogenic systemic fibrosis (NSF), for which deep excisional dermal biopsy including fascia is essential [14]

1) Increased Cellularity (spindle/epitheliod) with few other inflammatory cells

2) CD34+ spindle or epetheliod cells in reticular or tram-track arrangement

3) Both fine collagen and ropey collagen surrounded by clefts

4) Elastic fibers preserved (score -1 if elastic fibers absent)

5) Septal involvement

6) Osseous metaplasia (score +3 )

confirmation, this is likely an overestimate. The NSF Registry at Yale holds a little more than 360 cases, and a recent review counted 408 biopsy-confirmed cases of NSF in the literature [18]. Confirmed cases of NSF have been reported in patients from 8 years to 87 years old, with a peak incidence at ages $51-$ 60 years. There is no significant gender or racial predilection.

The natural history of NSF is variable [19]. As the condition progresses, the skin may take on a woody texture. Joint contractures or reduced range of movement are seen in $>60 \%$ of patients [18]. Of 345 patients in the NSF Registry in 2009, almost $10 \%$ were known to be restricted to a wheelchair (ICNSFR http://www.icnsfr.org). It is estimated that $5 \%$ of patients have a rapidly progressive course, and NSF may increase mortality rates through restricted mobility and, more rarely, restricted ventilation [6]. However, there is a high level of background morbidity, and no controlled trials have explored mortality directly attributable to NSF. One study of non-biopsy-proven cases suggested a $48 \%$ mortality rate over 48 months in patients with features of NSF compared with $20 \%$ in hemodialysis patients without cutaneous disease [20].

\section{Evidence for a link with gadolinium-based contrast agents}

Gd-based contrast agents exploit the paramagnetic nature of the $\mathrm{Gd}^{3+}$ cation (bound to a chelating agent in clinical

Table 3 Proposed combined clinical and histological scoring system for the diagnosis of nephrogenic systemic fibrosis (NSF)

\begin{tabular}{|c|c|}
\hline Clinical score & Histological score \\
\hline $\begin{array}{c}4=\text { Consistent with NSF } \\
(>1 \text { major criteria })\end{array}$ & $\begin{array}{c}4=\text { Consistent with NSF } \\
\quad(4 \text { or } 5 \text { criteria })\end{array}$ \\
\hline $\begin{array}{c}3=\text { Suggestive of NSF } \\
(1 \text { major criteria })\end{array}$ & $3=$ Suggestive of NSF ( 3 criteria) \\
\hline $\begin{array}{c}2=\text { Inconsistent with NSF } \\
(>1 \text { minor criteria })\end{array}$ & $2=$ Inconsistent with NSF ( 2 criteria) \\
\hline $\begin{array}{l}1=\text { NSF ruled out } \\
\quad(0-1 \text { minor criteria })\end{array}$ & $1=\mathrm{NSF}$ ruled out $(1$ criteria $)$ \\
\hline $\begin{array}{l}0=\text { Diagnostic of an entity } \\
\text { other than NSF }\end{array}$ & $0=$ Another diagnosis can be made \\
\hline
\end{tabular}


Fig. 1 a Hyperpigmented brawny-patterned plaques (major criterion). Red to violaceous thin, fixed plaques showing polygonal, reticular, or amoeboid morphologies (with permission from [15]). b Joint contractures (major criterion): end-stage NSF with fixed contracture of the knee (reprinted with permission [17]. c Cobblestoning (major criterion): This bumpy pattern resembles rounded paving stones (reprinted with permission [17]
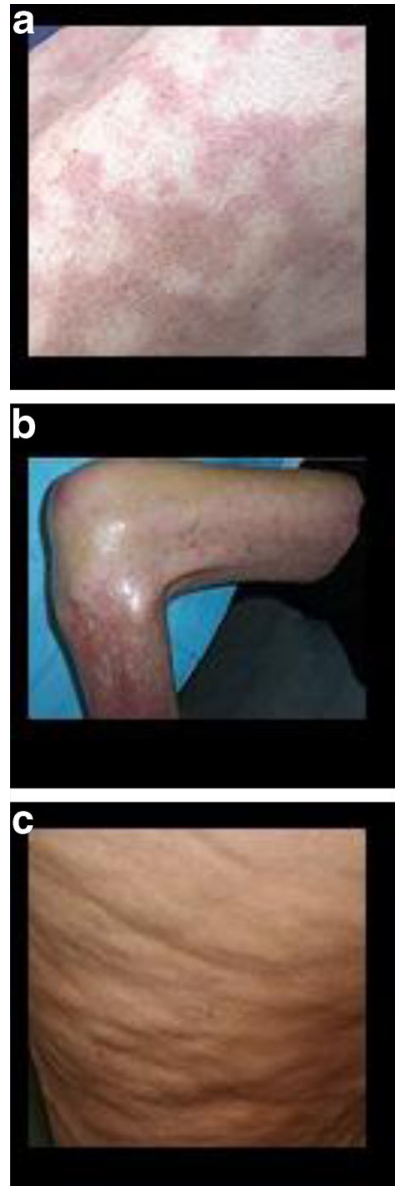

preparations), increasing the relaxation rate and thereby the MRI signal on T1-weighted sequences [21]. The main uses are: (1) highlighting inflammation and neoplasia, and (2) in magnetic resonance angiography (MRA). Nonenhanced MRA is now commonly available, but there remains a large group of patients across a range of specialties in whom Gd-based contrast agents provide added diagnostic information.

The factor common to all patients with NSF is renal impairment, in particular, end-stage kidney disease. Before 2006, risk factors identified from individual case reports and small retrospective series failed to identify a single agent that came close to satisfying the Hill criteria for causality [22]. NSF was frequently reported immediately following proinflammatory events or in hypercoagulable states, with preceding surgery in up to $90 \%$ of cases [11]. Erythropoietin use was seen in up to $80 \%$, although this may simply have reflected erythropoietin resistance relating to chronic inflammation [23]. Other risk factors, including liver disease [24], immunosuppression [25], hyperphosphatemia [26], and acidosis [2], were reported but not consistently reproduced. At this stage, it appeared that NSF involved a process of sensitizing events (renal disease and some proinflammatory condition) and an unidentified trigger (e.g., allergen deposition) [27].
In 2006, Groebner reported a series of five patients with end-stage kidney disease who developed NSF 2-4 weeks following Gd-enhanced MRA [2]. This association with Gd sparked immediate research into its possible role in NSF, and case series and retrospective case-control analyses have subsequently reported Gd-based contrast administration prior to NSF onset in nearly all cases [26, 28] (Table 4).

The reported delay between Gd exposure and NSF presentation varies greatly for individual patients, ranging from a few days to 3 years, with a median of 62 days [18]. The incidence of NSF following Gd administration in renally impaired patients varies between $0 \%$ and $18 \%$. The highest incidence has been seen in perioperative renal transplant patients on maintenance peritoneal dialysis undergoing highdose MRA [3]. A 2008 meta-analysis of 4,276 patients with renal impairment found strong and consistent increased risk of developing NSF for patients exposed to Gd compared with those not exposed [odds ratio (OR) 26.7, $95 \%$ confidence interval (CI) 10.3-69.4] [41].

Several reports suggest a dose-response relationship, and it is interesting to note that the first known cases of NSF, which occurred in 1997, followed a 1993 FDA approval of doubleand triple-dose gadodiamide MRA [31]. Data on the type and dose of Gd used is not available in all studies. For those studies that do report dose-effect, an increased NSF risk with either increasing cumulative Gd dose over multiple examinations or with a high single dose during a single examination is recorded [30, 33, 36, 42-44]. One observational study reports an average $2.4 \%$ risk of developing NSF for each radiological study using $\mathrm{Gd}$ in at-risk patients [32].

Boyd et al. were the first to detect Gd in NSF-related skin lesions in 2007 [45]. Their findings were subsequently reproduced-including at autopsy where extracellular Gd was found in multiple organs in patients with NSF. Gd deposits are rarely seen in exposed patients who have not developed NSF, and no deposits have been found in nonexposed patients [46]. It is postulated that $\mathrm{Gd}$ dissociation leads to insoluble $\mathrm{Gd}$ salt deposition in the interstitium, providing a nidus for fibrosis [47]. Free Gd has indeed been shown to stimulate human fibroblast proliferation in vitro, with hyaluronan and collagen synthesis, as seen in biopsies from patients with NSF [48]. Although the majority of the in vitro studies relate to nonchelated $\mathrm{Gd}$ as a trigger for NSF, human macrophages and monocytes also express pro-fibrotic cytokines and growth factors capable of stimulating NSF-like fibrosis in response to chelated gadodiamide and gadopentetate dimeglumine [49]. Several NSF-patients in whom no Gd exposure could be ascertained have been reported $[33,50]$. These include patients with solid-organ transplants, one of whom had positive lupus anticoagulant, and one with confirmed vascular thrombosis and hepatitis $\mathrm{C}$.

In summary, for approximately $90 \%$ of cases, there is a clear temporal sequence between Gd administration and NSF 
Table 4 Risk of nephrogenic systemic fibrosis (NSF) in patients with renal impairment exposed to gadolinium (Gd)-based contrast agents. This includes odds ratio (where available) for developing NSF following exposure

\begin{tabular}{|c|c|c|c|c|}
\hline & Patients exposed to $\mathrm{Gd}$ & No. of NSF cases & Risk of NSF after Gd exposure & $\begin{array}{l}\text { Odds ratio for } \\
\text { developing NSF }\end{array}$ \\
\hline Marckmann [29] & 370 CKD 5 & 13 & $3.5 \%$ & 32.5 \\
\hline Kallen [30] & Case-control, patients on dialysis and with AKI & $\begin{array}{l}19 \text { cases, } \\
57 \text { controls }\end{array}$ & $\begin{array}{l}0.6 \%(\mathrm{HD}) \\
4.6 \%(\mathrm{PD})\end{array}$ & 8.97 \\
\hline Broome [31] & 301 dialysis & 12 & $4.0 \%$ & 22.3 \\
\hline Deo [32] & 87 dialysis & 3 & $\begin{array}{l}3.4 \% \\
2.4 \% \text { risk for each Gd exposure }\end{array}$ & 31.5 \\
\hline Collidge [33] & 421 dialysis & 14 & $3.1 \%$ & \\
\hline Othersen [28] & 261 dialysis & 4 & $1.5 \%$ & $\begin{array}{l}6.67 \text { for single exposure } \\
44.5 \text { for multiple exposures }\end{array}$ \\
\hline Wiginton [34] & 72 dialysis & 2 & $2.8 \%$ & $0.82(95 \%$ CI $0.04-18.10)$ \\
\hline Prince [35] & $\begin{array}{l}265 \text { CKD } 5 \\
120 \mathrm{AKI}\end{array}$ & $\begin{array}{l}1 \\
11\end{array}$ & $\begin{array}{l}0.4 \% \\
9.2 \%\end{array}$ & \\
\hline Sadowski [36] & 393 CKD 3-5 & 13 (6 on HD) & $3.3 \%$ & \\
\hline Lauenstein [37] & 312 dialysis & 9 & $2.6 \%$ & \\
\hline Rydahl [3] & $102 \mathrm{CKD} 5$ & 18 & $18 \%$ & \\
\hline Shabana [38] & 414 dialysis & 12 & $2.9 \%$ & \\
\hline Chrysochou [39] & 2053 CKD 2-5 & 0 & $0 \%$ & \\
\hline Heinz-Peer [40] & 367 dialysis & 6 & $1.6 \%$ & \\
\hline Bahrami [25] & 209 dialysis & 4 & $1.9 \%$ & \\
\hline
\end{tabular}

$C K D$ chronic kidney disease; $A K I$ acute kidney injury; $H D$ hemodialysis; $P D$ peritoneal dialysis, $C I$ confidence interval

development. Data show a strong association between Gd exposure and NSF, and there is a likely dose-response relationship. This suggests a causal link. The validity of adult data extrapolated to children is unknown.

\section{Role of different gadolinium-based contrast agents}

Free Gd is toxic and may cause splenic degeneration, central lobular hepatic necrosis, competitive calcium-channel inhibition, and a variety of hematological pathologies [51]. The different classes of $\mathrm{Gd}$ chelates used clinically are ionic or nonionic ligand-binding groups within either linear, nonlinear, or macrocyclic molecules that trap Gd and facilitate renaland to a lesser extent, hepatic - excretion (Table 5). Their plasma half life is around $2 \mathrm{~h}$ in people with normal renal function and $30 \mathrm{~h}-120 \mathrm{~h}$ in those with renal impairment [53].

If, as postulated, free Gd stimulates NSF, increased dissociation from chelating compounds should result in increased NSF risk. Dissociation increases with reduced clearance (renal impairment), low thermodynamic and kinetic stability of some Gd contrast agents, and acidosis. The predominant process responsible for dissociation is thought to be transmetallation with endogenous zinc ions (and to a lesser extent with copper, calcium, or iron ions). Chelates have different thermodynamic and kinetic stabilities. Although kinetic stability plays a more significant role than thermodynamic stability in vivo [54], both reduce in a similar order: macrocyclic ligands have high stability, ionic open-chain ligands moderate stability, and nonionic open-chain chelates the lowest stability [51]. In rats, administration of different contrast agents has been shown to induce NSF-like cutaneous fibrosis and Gd deposits following gadodiamide administration, but no such reaction is seen for other agents, including gadoversetamide, gadopentetate dimeglumine, gadobenate dimeglumine, gadoterate meglumine, and gadobutrol [55]. Human studies in patients with normal renal function have confirmed two- to four-times higher concentrations of $\mathrm{Gd}$ in bone following gadodiamide than the macrocyclic preparation gadoteridol [56].

Retrospective analysis of the role of different agents is limited, as the specific agent is often either not recorded or because any one patient may have been exposed to multiple contrast agents. A review in 2008 reported unconfounded association to be most frequent for gadodiamide, followed by gadopentetate dimeglumine. Confounded association has been reported with both linear and macrocyclic Gd contrast agents [57], as are cases of NSF after unconfounded exposure to the macrocyclic agents gadobutrol and gadoterate meglumine [58]. In reality, there is inadequate data to evaluate whether the risk of NSF varies significantly between different contrast agents due to: (1) the small total number of cases of NSF; (2) uncertainty of the specific agent used; (3) the large proportion of market share possessed by gadopentetate dimeglumine and gadodiamide in the relevant time period. Interaction between chelate stability, prolonged contrast-agent circulation, and 
Table 5 Gadolinium (Gd) contrast agents, their approval status in the USA and Canada, and classification as high, medium, or low risk in Europe. In Europe, with the exception of Optimark, individual Gd agents are approved for clinical use on a national rather than central level

\begin{tabular}{|c|c|c|c|c|}
\hline Brand name & Product & Excretion [52] & US FDA approval & Canadian TPD approval \\
\hline \multicolumn{5}{|l|}{ High-risk (EU classification) } \\
\hline Omniscan (linear chelate) & Gadodiamide Gd-DTPA-BMA & Renal & $\begin{array}{l}\text { Adult CNS, body } \\
\text { Pediatric CNS, body } \\
>2 \text { years }\end{array}$ & $\begin{array}{l}\text { Adult CNS, body, breast, } \\
\text { MRA } \\
\text { Pediatric CNS }>2 \text { years, } \\
\text { CI in NN }\end{array}$ \\
\hline Optimark (linear) & $\begin{array}{l}\text { Gadoversetamide } \\
\text { Gd-DTPA-BMEA }\end{array}$ & Renal & $\begin{array}{l}\text { Adult CNS, liver } \\
\text { No pediatric approval- } \\
\text { caution }<18 \text { years }\end{array}$ & $\begin{array}{l}\text { Adult } \mathrm{CNS} \text {, liver } \\
\text { No pediatric approval- } \\
\text { caution }<18 \text { years, } \\
\mathrm{CI} \text { in } \mathrm{NN}\end{array}$ \\
\hline Magnevist (linear) & $\begin{array}{l}\text { Gadopentetate dimeglumine } \\
\text { Gd-DTPA }\end{array}$ & Renal & $\begin{array}{l}\text { Adult CNS, body, head/neck. } \\
\text { Pediatric CNS, body, } \\
\text { head/neck }>2 \text { years. }\end{array}$ & $\begin{array}{l}\text { Adult CNS, head/neck } \\
\text { Pediatric CNS }>2 \text { year,s } \\
\quad \text { CI in NN }\end{array}$ \\
\hline \multicolumn{5}{|l|}{ Medium risk (EU classification) } \\
\hline Multihance (linear) & Gadobenate dimeglumine BOPTA & $97 \%$ renal, $3 \%$ biliary & $\begin{array}{l}\text { Adult CNS, MRA } \\
\text { Pediatric CNS }>2 \text { years }\end{array}$ & $\begin{array}{l}\text { Adult CNS, MRA } \\
\text { Pediatric CNS }>2 \text { years }\end{array}$ \\
\hline $\begin{array}{l}\text { Primovist (Eovist in USA) } \\
\text { (linear) }\end{array}$ & $\begin{array}{l}\text { Gadoxetate disodium } \\
\text { Gd-EOB-DTPA }\end{array}$ & $50 \%$ renal, $50 \%$ biliary & $\begin{array}{l}\text { Adult MRI liver } \\
\text { Not approved }<18 \text { years }\end{array}$ & $\begin{array}{l}\text { Adult MRI liver } \\
\text { Not approved }<18 \text { years }\end{array}$ \\
\hline $\begin{array}{l}\text { Vasovist (Ablavar in } \\
\text { USA and Canada) (linear) }\end{array}$ & Gadofosveset trisodium MS325 & $91 \%$ renal, $9 \%$ biliary & $\begin{array}{l}\text { Adult MRA } \\
\text { Not approved }<18 \text { years }\end{array}$ & $\begin{array}{l}\text { Adult MRA } \\
\text { Not approved }<18 \text { years }\end{array}$ \\
\hline \multicolumn{5}{|l|}{ Low risk (EU classification) } \\
\hline $\begin{array}{r}\text { Gadovist (Gadavist in } \\
\text { USA) (macrocyclic) }\end{array}$ & Gadobutrol Gd-BT-DO3A & Renal & $\begin{array}{l}\text { Adult and pediatric } \\
\text { CNS }>2 \text { years }\end{array}$ & $\begin{array}{l}\text { Adult CNS, MRA } \\
\text { Pediatric CNS, } \\
\quad \text { MRA }>2 \text { years }\end{array}$ \\
\hline Prohance (macrocyclic) & Gadoteridol GD-HP-DO3A & Renal & $\begin{array}{l}\text { Adult CNS, head/neck } \\
\text { Pediatric } C N S>2 \text { years }\end{array}$ & $\begin{array}{l}\text { Adult CNS, head/neck } \\
\text { Pediatric } C N S>2 \text { years }\end{array}$ \\
\hline Dotarem (macrocyclic) & $\begin{array}{l}\text { Gadoterate meglumine } \\
\text { Gd-DOTA }\end{array}$ & Renal & $\begin{array}{l}\text { Adult and pediatric } \\
\text { CNS }>2 \text { years }\end{array}$ & No listing \\
\hline
\end{tabular}

$E U$ European Union, $C N S$ central nervous system: brain, spine, and surrounding structures, MRA magnetic resonance angiography. $C I$ in $N N$ contraindicated in neonates up to 4 weeks, FDA Food and Drug Administration, TPD Canadian Therapeutic Products Directorate

tissue $\mathrm{pH}$ leading to Gd release therefore remains incompletely understood, as is the role of Gd in the uncontrolled proliferation of fibrocytes in NSF.

\section{NSF risk: renal impairment and liver disease}

Up to December 2010, $79 \%$ of patients with NSF recorded in the Yale Registry were receiving renal dialysis, and $17 \%$ were nondialyzed patients with acute kidney injury (AKI), unspecified renal insufficiency, or chronic kidney disease (CKD) stage 4 or 5 . The remaining were in the immediate post-renal-transplant period [16]. Until 2011, no cases of NSF had been reported in CKD stage 3, and there were limited reports in CKD stage $4[39,59]$. One recent study from 2011, however, reported three cases of NSF in patients with CKD stage 3 and 4 [58]. An association with liver disease has been reported, some of which are within the peritransplant period, although this is in a small number of cases, and concomitant renal impairment is present in all cases. A review of $335 \mathrm{NSF}$ cases in 2009 confirmed liver disease in 41 patients but failed to demonstrate any statistically significant increased risk due to the liver disease alone. Renal impairment was severe in all cases bar one, in which AKI was described [24]. The conclusion drawn in the European and American guidelines is that patients most at risk of NSF are those with CKD stage 4 or 5, including those needing dialysis and those with reduced renal function who have or are awaiting liver transplantation. Patients with CKD stage 3 (glomerular filtration rate $30-59 \mathrm{ml} /$ min) and children $<1$ year of age are considered to have moderately increased risk [60].

\section{Published guidelines}

In May 2006, the Danish Medicines Agency reported 25 cases of NSF in Europe among patients with recent gadodiamide exposure. One month later, the US FDA advised that Gd contrast be used only if clearly necessary in patients with CKD stage 4-5 [60]. The approval status of commonly available Gd preparations in different jurisdictions is summarized in Tables 5 and 6. 
Table 6 Summary of the 2010 European Medicines Agency guidelines (www.ema.europa.eu). Gadolinium-based contrast agents (GBCA) are risk stratified as shown in Table 5

\begin{tabular}{|c|c|}
\hline Patients at risk & Risk stratification \\
\hline $\begin{array}{l}\text { Patients with severely } \\
\text { impaired renal function }\end{array}$ & $\begin{array}{l}\text { High-risk GBCAs: Contra-indicated } \\
\text { Medium- and low-risk GBCAs: use lowest } \\
\text { possible dose, pause of } 7 \text { days between } \\
\text { two GBCA enhanced procedures }\end{array}$ \\
\hline $\begin{array}{l}\text { Patients with moderately } \\
\text { impaired renal function }\end{array}$ & $\begin{array}{l}\text { High-risk GBCAs: Use single injection of } \\
\text { minimum dose, pause } 7 \text { days between } \\
\text { two GBCA enhanced procedures } \\
\text { Medium- and low-risk GBCAs: Use } \\
\text { minimum dose, pause } 7 \text { days between } \\
\text { two GBCA enhanced procedures }\end{array}$ \\
\hline Infants $<1$ year & $\begin{array}{l}\text { High-, medium-, and low-risk GBCAs: } \\
\text { Use single injection of minimum dose, } \\
\text { pause } 7 \text { days between two GBCA } \\
\text { enhanced procedures }\end{array}$ \\
\hline Neonates $<4$ weeks & $\begin{array}{l}\text { High-risk GBCAs: Contraindicated } \\
\text { Medium- and low-risk GBCAs: Use } \\
\text { lowest possible minimum dose, pause } \\
7 \text { days between two GBCA enhanced } \\
\text { procedures }\end{array}$ \\
\hline Breast-feeding mothers & $\begin{array}{l}\text { High-risk GBCAs: Pause for } 24 \mathrm{~h} \\
\text { Medium- and low-risk GBCAs: Consider } \\
\text { pause for } 24 \mathrm{~h}\end{array}$ \\
\hline $\begin{array}{l}\text { Perioperative phase of liver } \\
\text { transplantation }\end{array}$ & $\begin{array}{l}\text { High-risk GBCAs: Contraindicated } \\
\text { Medium and low risk GBCAs: Use lowest } \\
\text { possible minimum dose, pause } 7 \text { days } \\
\text { between two GBCA enhanced } \\
\text { procedures }\end{array}$ \\
\hline
\end{tabular}

In 2007, US FDA (http://www.FDA.gov) and European Society of Urogenital Radiology (ESUR) (http://www.esur.org) guidelines warned of the increased risk in acute or chronic severe renal insufficiency, hepatorenal syndrome, and the perioperative liver transplantation period. The European Medicines Agency (EMA) (http://www.ema.europa.eu) guidelines named gadodiamide, gadopentetate dimeglumine, and gadoversetamide as high risk and as being contraindicated in patients with GFR $<30 \mathrm{ml} / \mathrm{min} / \mathrm{m}^{2}$. They also advised caution in patients with CKD stage 3 or in children $<1$ year old (Table 6 ). In 2009, the EMA's recommended that high-risk Gd-based contrast agents are avoided in neonates, and the minimum dose is used in infants up to 1 year old and with CKD stage 3. For medium- and low-risk Gd agents, minimum dose was recommended in, among other groups, neonates and infants up to 1 year [61]. The 2010 FDA guidelines contraindicate high-risk Gd contrast agents in patients with AKI or CKD stage 4-5 [60]. The FDA also suggests prompt hemodialysis following Gd for those already on hemodialysis, although this practice is not encouraged by the EMA.

Taking sales figures as a surrogate for quantities of $\mathrm{Gd}$ prescribed, there has been a decrease in worldwide sales of gadodiamide (the agent most frequently associated with NSF) since 2007 against a backdrop of increasing sales prior to this period (Evaluate Pharma, London, UK, 2012; http://www. evaluategroup.com). This is despite an increase in the overall number of MRI scans performed after 2007 (Food and Drugs Administration Joint Meeting of the Cardiovascular and Renal Drugs and Drug Safety and Risk Management Advisory Committees, December 2009; http://www.FDA.gov). This reflects a culture shift highlighted by a recent report of widely adopted policy changes among nephrologists across the USA relating to Gd contrast use in renal impairment and awareness of the risk factors and morbidity associated with NSF[62]. Since 2007, there has been a dramatic drop in the number of NSF cases reported, with multiple large studies in Sweden and the USA identifying reduced incidence or no new cases of NSF following restrictive prescribing policies [42, 44, $59,63]$. In particular, no new pediatric cases of NSF have been reported to the Yale Registry in the period 2007-2013 (personal communication, Yale NSF Registry). These results are promising and imply that NSF is unlikely to occur if guidelines limiting Gd-based contrast administration are followed. However, in 2009, well after introduction of guidelines, there was a wide variation in practice across institutions in the UK, where some departments were not adhering to European guidelines [64].

\section{Treatment and prevention}

Gd administration is sometimes essential for diagnostic performance of MRI, even in patients with acute or chronic renal failure. Hemodialysis reduces serum Gd concentration following exposure. A single session of hemodialysis removes 74 $78 \%$ of circulating contrast, and three consecutive sessions over 6 days eliminate up to $98.9 \%$ [65]. However, Broome et al. described four patients who developed NSF despite receiving daily dialysis for three consecutive days starting within $24 \mathrm{~h}$ of contrast administration. None of these patients started dialysis immediately, with the shortest delay being $9 \mathrm{~h}$ [66]. The FDA advises that in patients already undergoing regular hemodialysis, there may be some benefit in scheduling a session immediately following Gd administration [60], although there is only scant evidence that this reduces the risk of NSF [67]. Initiating hemodialysis purely to eliminate $\mathrm{Gd}$ in renal impairment is advised against [60]. Continuous ambulatory peritoneal dialysis for 20 days clears just $69 \%$ of the injected dose of $\mathrm{Gd}$ [68] and is not advised as a technique to remove Gd-based contrast agents.

Once NSF has developed, the factor most consistently associated with resolution of symptoms is improved renal function. This benefit is seen in patients with chronic renal failure who have undergone successful renal transplantation and in patients whose AKI has resolved [69]. No cases of complete remission have been described in the presence of 
continued renal impairment [18]. Improvement in cutaneous changes associated with NSF in patients with improving renal function is sufficiently convincing that caution must be applied to the interpretation of results from studies reporting successful treatments for NSF in patients with concomitantly improving renal function.

Despite a myriad of other treatment options that have been proposed, the evidence is anecdotal and comes from case series and small, uncontrolled trials. No single treatment has convincingly shown consistent benefit. Physiotherapy is reported to maintain mobility in affected joints [70]. Extracorporeal photophoresis has among the largest numbers of case series but with mixed results. Studies of at least seven patients show plaque softening and improved joint mobility [71-73]. One patient with NSF for $<1$ year had complete regression of skin changes [71]. Mild improvement in skin tightening and range of motion was seen in only three of five patients treated in one series [73]. Other therapies with reported benefit include sodium thiosulphate [74], rapamycin [75], imatinib mesylate [76], and pentoxifylline [2]. Limited success has been seen with immune modulators, such as glucocorticoids [77], thalidomide, immunoglobulins [78], and plasmapheresis [79]. A common limitation of these studies is confounding by concomitantly improving renal function.

\section{NSF and GFR estimation in children}

Only ten children, all $>6$ years, have been recorded with biopsy-confirmed NSF by the Yale Registry to 2013 (personal communication, Yale NSF Registry). There is insufficient data to determine specific risk factors for NSF in children $[4,80]$. Current guidelines advise against administration of high-risk Gd agents to neonates and advise caution in infants [60, 61]. This is based on the hypothesis that immature renal function in neonates and children puts them at increased risk of NSF.

Renal clearance of Gd agents occurs via passive glomerular filtration [51]. In a healthy term baby, GFR of approximately $26 \mathrm{ml} / \mathrm{min} / 1.73 \mathrm{~m}^{2}$ at birth increases rapidly during the first 2 weeks of life, with a slower rise until 1-2 years, at which age GFR corrected for body surface area is comparable with adult levels [81]. As nephrogenesis is incomplete until 34 weeks' gestational age, this increase is delayed for premature and very-low-birth-weight infants.

Clinical GFR estimation from serum creatinine is limited by physiologic variation between individuals in the first weeks of life, as well as inconsistent creatinine assay standardization between institutions [82]. As a result, no single method is universally employed to calculate GFR. Methods reported in a recent survey of pediatric MRI practices include application of the Schwartz formula to serum creatinine and comparison of serum creatinine with age-appropriate normal ranges [83]. Alternative markers, such as cystatin- $\mathrm{C}$, may provide a more accurate estimate, but reference levels have yet to be defined for neonates [84].

No diagnoses of NSF have ever been made in neonates or infants despite thousands of Gd-enhanced MRI examinations performed. Our institution has a large pediatric renal unit, with up to 30 renal transplantations per year. Prior to 2007, Gd was used at doses of up to $0.3 \mathrm{mmol} / \mathrm{kg}$ in children with renal impairment undergoing contrast-enhanced MRA (gadopentetate dimeglumine), often as part of pretransplant workup. Between 2002 and 2007, 75 nephrology patients (neonate to 19 years of age, median 9.6 years) underwent 93 contrast-enhanced MRI scans. No cases of NSF were identified in this high-risk cohort over at least 6 months of follow-up [4]. It remains that ageappropriate GFR levels at which it is safe to administer Gd have yet to be determined (FDA Joint Advisory Committee 2008, http://www.FDA.gov).

One may speculate that NSF risk in children is not simply related to GFR. One hypothesis is that the inflammatory response to $\mathrm{Gd}$ is not triggered in the infant's immature immune system [18], and this raises the question of whether current guidelines are entirely justified [80]. The unwanted effect of restricting the use of contrast-enhanced MRI may be an increase in the use of computed tomography (CT) and thereby an increase in the exposure of children to ionizing radiation.

Our own experience is that it is feasible to identify children with increased likelihood of low renal function (e.g., infants, those with a history of renal disease, or children referred from certain specialties such as nephrology, urology, or oncology). This allows a simple pathway for measuring serum creatinine and estimating GFR in high-risk children, which again allows adherence to the guidelines without restricting the overall use of contrast-enhanced MRI in children. Where possible, for neonates, we suggest delaying Gd contrast administration until renal function has matured.

\section{Alternative imaging strategies in children}

Although imaging sequences in MRI are able to maximize intrinsic contrast between tissue types, Gd-based contrast agents provide further information relating to perfusion, microvascular density, and capillary permeability, information that may be invaluable. As in any aspect of medicine, the risks, benefits, and alternatives of Gd administration must be assessed. For children, options are: (1) proceed with contrastenhanced MRI despite the risk, using lower-risk macrocyclic agents and minimizing dose, (2) perform nonenhanced MRI, adapting the imaging sequence if possible, and (3) use a different modality (ultrasound or CT) [85]. In patients with renal impairment, the risk of nephropathy caused by iodinated contrast agents used for CT should be considered before choosing $\mathrm{CT}$ as an alternative to MRI. The role of microbubble contrast 
ultrasound in detecting microvascular and macrovascular lesions has been described in liver, carotid, and cardiac imaging. However, the potential risks of these agents are incompletely understood, and they are at present not licensed in pregnancy and children [86]. A range of nonenhanced MRI techniques are now available to depict vascular anatomy [87] and includes a technique of inverting the magnetic vector in a specific volume of tissue, then allowing time $(0.5-2 \mathrm{~s})$ for noninverted blood to enter this volume and finally acquire the images, which will then predominantly comprise signal from the intravascular spaces. If still using Gd-based contrast agents, good image quality is achieved with quarter-dose gadobenatedimeglumine-enhanced abdominal MRI at 3 Tesla, although tissue contrast and objective enhancement is improved at half dose $(0.05 \mathrm{mmol} / \mathrm{kg})$ [88]. Whether this may be applied to 1.5 Tesla scanners (the most widely used field strength) and whether this further reduces the risk of NSF in renal impairment warrants further investigation. Similarly, low-dose protocols can yield good diagnostic image quality in MRA [89].

\section{Conclusion}

Although only confirmed in around 400 patients worldwide, NSF carries considerable morbidity and in rare cases may be fatal. There is a consistent body of evidence showing a significantly increased risk of NSF following Gd-based contrastagent administration. The temporal relationship, dose-response effect, and Gd deposition in NSF plaques suggests a causal relation. Following the introduction of international guidelines limiting the prescription of Gd-based contrast agents and classifying individual agents as high, medium, or low risk, there has been reduced incidence of NSF. Ten children with NSF have been reported to date, none $<6$ years of age, and all developing symptoms prior to the introduction of the guidelines. Although evidence in children is scant, current guidelines extrapolate from adult data and urge extra caution in pediatric imaging. Vigilance when planning MRI, the use of nonenhanced MRI for vascular imaging, and the use of reduced-dose Gd in high-risk children are suggested as important preventative measures.

\section{Questions (Answers provided following the reference list)}

1. In relation to Gd-based contrast agents:

a. They are used in MRI, mainly to highlight inflammation and neoplasia, and in MRA

b. In a patient with renal impairment, $\mathrm{Gd}$ contrast agents are preferable to iodinated contrast media as used in CT

c. They can be effectively removed with hemodialysis, avoiding development of nephrogenic systemic fibrosis d. Nonchelated Gd is highly toxic in vivo, causing encephalopathy, hemolysis, anemia, and nephrotoxicity

e. They have a higher rate of non-NSF-related adverse events compared with iodinated contrast used in CT

2. The following statement relating to the clinical features of nephrogenic systemic fibrosis is NOT true:

a. Features can include hyperpigmented patches, skin thickening, and joint contractures

b. NSF may appear clinically similar to other dermatological conditions, such as scleroderma

c. NSF typically occurs rapidly following exposure to $\mathrm{Gd}$

d. The clinical picture is variable and must be assessed in combination with histopathological features from deep-skin biopsy in order to make a confident diagnosis

e. Clinical changes can improve following restoration of a patient's renal function

3. For patients with NSF:

a. $15 \%$ have a rapidly progressive course

b. There is a $48 \%$ mortality rate attributable to NSF

c. Most patients become wheelchair bound due to restricted mobility

d. There are more than 500 biopsy-confirmed cases in the literature

e. In a patient with continuing renal impairment, no treatment has been consistently shown to improve symptoms of NSF

4. With regard to risk minimization for NSF:

a. Dialysis following Gd contrast administration consistently prevents the development of NSF

b. Gadodiamide (Omniscan), gadoversetamide (Optimark), and gadopentetate dimeglumine (Magnevist) are classified as high risk for NSF and are contraindicated in patients with severely impaired renal function

c. Gd contrast agents should never be used in neonates

d. It is safe for women to continue breast feeding following Gd administration

e. Incidence of NSF has not dropped significantly since the implementation of guidelines limiting $\mathrm{Gd}$ contrast agent administration

5. Relating to NSF in children:

a. NSF is more common in neonates and infants than in older children

b. Creatinine blood testing is mandatory in all patients prior to $\mathrm{Gd}$ administration

c. Gd use is essential to MRA

d. Gadoversetamide (Optimark) is contraindicated in neonates

e. Risk of NSF means that there is an absolute contraindication to the use of Gd in patients with renal impairment, and an alternative imaging modality must be used 


\section{References}

1. Cowper S, Robin H, Steinberg S (2000) Scleromyxoedemalike cutaneous diseases in renal-dialysis patients. Lancet 356(9234):1000-1001

2. Grobner T (2006) Gadolinium - a specific trigger for the development of nephrogenic fibrosing dermopathy and nephrogenic systemic fibrosis? Nephrol Dial Transplant 21(4):1104-1108

3. Rydahl C, Thomsen HS, Marckmann P (2008) High prevalence of nephrogenic systemic fibrosis in chronic renal failure patients exposed to gadodiamide, a gadolinium-containing magnetic resonance contrast agent. Invest Radiol 43(2):141-144

4. Mendichovsky IA, Marks SD, Simcock CM, Olsen OE (2007) Gadolinium and nephrogenic systemic fibrosis: time to tighten practice. Pediatr Radiol 38(5):489-496

5. Ting WW, Stone MS, Madison KC, Kurtz K (2003) Nephrogenic fibrosing dermopathy with systemic involvement. Archiv Dermatol 139(7):903-906

6. Kucher C, Steere J, Elenitsas R, Siegel DL, Xu X (2006) Nephrogenic fibrosing dermopathy/nephrogenic systemic fibrosis with diaphragmatic involvement in a patient with respiratory failure. J Am Acad Dermatol 54(2):S31-S34

7. Levine JM, Taylor RA, Elman LB, Lavi E, Stolzenberg ED, McGarvey ML, Asbury AK, Jimenez SA (2004) Involvement of skeletal muscle in dialysis-associated systemic fibrosis (nephrogenic fibrosing dermopathy). Muscle Nerve 30(5):569-577

8. Lekawanvijit S, Kompa AR, Manabe M, Wang BH, Langham RG, Nishijima F, Kelly DJ, Krum H (2012) Chronic kidney diseaseinduced cardiac fibrosis is ameliorated by reducing circulating levels of a non-dialysable uremic toxin, indoxyl sulfate. PLoS One 7(7): e41281

9. Huggins JT, Sahn SA (2004) Causes and management of pleural fibrosis. Respirology 9(4):441-447

10. Knopp EA, Cowper SE (2008) Nephrogenic systemic fibrosis: early recognition and treatment. Semin Dial 21(2):123-128

11. Cowper SE (2003) Nephrogenic fibrosing dermopathy: the first 6 years. Curr Opin Rheumatol 15:785-790

12. Thakral C, Abraham J (2009) Nephrogenic systemic fibrosis: histology \& gadolinium detection. Radiol Clin N Am 47(5):841-853

13. Ortonne N, Lipsker D, Chantrel F, Boehm N, Grosshans E, Cribier B (2004) Presence of CD45RO+ CD34+ cells with collagen synthesis activity in nephrogenic fibrosing dermopathy: a new pathogenic hypothesis. British J Dermatol 150(5):1050-1502

14. Ruiz-Genao DP, Fraga S (2005) Osseous metaplasia in the setting of nephrogenic fibrosing dermopathy. J Cutan Pathol 32:172-175

15. Girardi M, Kay J, Elston DM, LeBoit PE, Abu-Alfa A, Cowper SE (2011) Nephrogenic systemic fibrosis: clinicopathological definition and workup recommendations. J Am Acad Dermatol 65(6):10951106

16. Braverman I, Cowper SE (2010) Nephrogenic systemic fibrosis. F1000 Med Rep 2:84

17. Girardi M (2008) Nephrogenic systemic fibrosis: a dermatologist's perspective. J Am Coll Radiol 5(1):40-44

18. Zou Z, Ma L (2011) Nephrogenic systemic fibrosis: review of 408 biopsy-confirmed cases. Indian J Dermatol 56(1):65-73

19. Mayr M, Burkhalter F, Bongartz G (2009) Nephrogenic systemic fibrosis: clinical spectrum of disease. J Magn Reson Imaging 30(6): 1289-1297

20. Todd DJ, Kagan A, Chibnik LB, Kay J (2007) Cutaneous changes of nephrogenic systemic fibrosis: predictor of early mortality and association with gadolinium exposure. Arthritis Rheum 56(10):3433-3441

21. Port M, Idée JM, Medina C, Robic C, Sabatou M, Corot C (2008) Efficiency, thermodynamic and kinetic stability of marketed gadolinium chelates and their possible clinical consequences: a critical review. Biometals 21(4):469-490
22. Hill AB (1965) The environment and disease: association or causation? Proc R Soc Med 58(5):295-300

23. Goveia M, Chan BP, Patel PR (2007) Evaluating the role of recombinant erythropoietin in nephrogenic systemic fibrosis. J Am Acad Dermatol 57:725-727

24. Mazhar SM, Shiehmorteza M, Ca K, Middleton MS, Sirlin CB (2009) Nephrogenic systemic fibrosis in liver disease: a systematic review. J Magn Reson Imaging 30(6):1313-1322

25. Bahrami S, Raman SS, Sauk S, Salehmoghaddam S, Villablanca JP, Finn JP, Lu DSK (2009) Ten-year experience with nephrogenic systemic fibrosis: case-control analysis of risk factors. J Comput Assist Tomogr 33(6):819-823

26. Prince MR, Zhang HL, Roditi GH, Leiner T, Kucharczyk W (2009) Risk factors for NSF: a literature review. J Magn Reson Imaging 30: 1298-1308

27. Cowper SE, Bucala R, Leboit PE (2006) Nephrogenic fibrosing dermopathy/nephrogenic systemic fibrosis-setting the record straight. Semin Arthritis Rheum 35(4):208-210

28. Othersen JB, Maize JC, Woolson RF, Budisavljevic MN (2007) Nephrogenic systemic fibrosis after exposure to gadolinium in patients with renal failure. Nephrol Dial Transplant 22(11):3179-3185

29. Marckmann P, Skov L, Rossen K, Dupont A, Damholt MB, Heaf JG, Thomsen HS (2006) Nephrogenic systemic fibrosis: suspected causative role of gadodiamide used for contrast-enhanced magnetic resonance imaging. J Am Soc Nephrol 17(9):2359-2362

30. Kallen AJ, Jhung M, Cheng S, Hess T, Turabelidze G, Abramova L, Arduino M (2008) Gadolinium-containing magnetic resonance imaging contrast and nephrogenic systemic fibrosis: a case-control study. Am J Kidney Dis 51(6):966-975

31. Broome DR, Girguis MS, Baron PW, Cottrell AC, Kjellin I, Kirk G (2007) Gadodiamide-associated nephrogenic systemic fibrosis: why radiologists should be concerned. Am J Roentgenol 188(2):586-592

32. Deo A, Fogel M, Cowper SE (2007) Nephrogenic systemic fibrosis: a population study examining the relationship of disease development to gadolinium exposure. Clin J Am Soc Nephrol 2(2):264-267

33. Collidge TA, Mark PB, Traynor JP, Jardine AG, Thomas S, Morris W, Simpson K (2007) Imaging and nephrogenic systemic fibrosis: retrospective study of a renal replacement therapy cohort. Radiology 245(1):168-175

34. Wiginton CD, Kelly B, Oto A, Jesse M, Aristimuno P, Ernst R, Chaljub G (2008) Gadolinium-based contrast exposure, nephrogenic systemic fibrosis, and gadolinium detection in tissue. Am J Roentgenol 190(4):1060-1068

35. Prince MR, Morris M, Macgregor JL, Grossman ME, Silberzweig J, Delapaz RL, Lee HJ, Margo CM, Valeri AM (2008) Incidence of nephrogenic systemic fibrosis at two large medical centers. Radiology 248(3):807-816

36. Sadowski EA, Bennett LK, Chan MR, Wentland AL, Garrett AL, Garrett RW (2007) Nephrogenic systemic fibrosis : risk factors and incidence estimation. Radiology 243(1):148-157

37. Lauenstein TC, Salman K, Morreira R, Tata S, Tudorascu D, Baramidze G, Singh-Parker S (2007) Nephrogenic systemic fibrosis: center case review. J Magn Reson Imaging 26(5):1198-1203

38. Shabana WM, Cohan RH, Ellis JH, Hussain HK, Francis IR, Su LD, Mukherji SK (2008) Nephrogenic systemic fibrosis: a report of 29 cases. Am J Roentgenol 190(3):736-741

39. Chrysochou C, Buckley DL, Dark P, Cowie A, Kalra PA (2009) Gadolinium-enhanced magnetic resonance imaging for renovascular disease and nephrogenic systemic fibrosis: critical review of the literature and UK experience. J Magn Reson Imaging 29:887-894

40. Heinz-peer G, Neruda A, Watschinger B, Vychytil A, Geusau A, Haumer M, Weber M (2010) Prevalence of NSF following intravenous gadolinium-contrast media administration in dialysis patients with endstage renal disease. Eur J Radiol 76(1):129-134

41. Agarwal R, Brunelli SM, Williams K, Mitchell MD, Feldman HI, Umscheid C (2009) Gadolinium-based contrast agents and 
nephrogenic systemic fibrosis: a systematic review and meta-analysis. Nephrol Dial Transplant 24(3):856-863

42. Martin DR, Krishnamoorthy SK, Kalb B, Salman KN, Sharma P, Carew JD, Martin P (2010) Decreased incidence of NSF in patients on dialysis after changing gadolinium contrast-enhanced MRI protocols. J Magn Reson Imaging 31(2):440-446

43. Altun E, Martin DR, Wertman R, Lugo-Somolinos A, Fuller ER, Semelka RC (2009) Nephrogenic systemic fibrosis: change in incidence following a switch in gadolinium agents and adoption of a gadolinium policy-report from two US Universities. Radiology 253(3):689-696

44. Wang Y, Alkasab TK, Kay J, Abujudeh HH (2011) Incidence of nephrogenic systemic fibrosis after adoption of restrictive gadoliniumbased contrast agent guidelines. Radiology 260(1):105-111

45. Boyd AS, Zic J, Abraham JL (2007) Gadolinium deposition in nephrogenic fibrosing dermopathy. J Am Acad Dermatol 56(1):27-30

46. Sanyal S, Marckmann P, Scherer S, Abraham JL (2011) Multiorgan gadolinium $(\mathrm{Gd})$ deposition and fibrosis in a patient with nephrogenic systemic fibrosis-an autopsy-based review. Nephrol Dial Transplant 26(11):3616-3626

47. High WA, Ayers RA, Chandler J, Zito G, Cowper SE (2007) Gadolinium is detectable within the tissue of patients with nephrogenic systemic fibrosis. J Am Acad Dermatol 56(1):21-26

48. Edward M, Quinn JA, Mukherjee S, Jensen M, Jardine AG, Mark PB, Burden AD (2008) Gadodiamide contrast agent "activates" fibroblasts : a possible cause of nephrogenic systemic fibrosis. J Pathol 214:584-593

49. Newton BB, Jimenez SA (2009) Mechanism of NSF: new evidence challenging the prevailing theory. J Magn Reson Imaging 30:12771283

50. Wahba IM, Simpson EL, White K (2007) Gadolinium is not the only trigger for nephrogenic systemic fibrosis: insights from two cases and review of the recent literature. Am J Transplant 7(10):2425-2432

51. Idée JM, Port M, Robic C, Medina C, Sabatou M, Corot C (2009) Role of thermodynamic and kinetic parameters in gadolinium chelate stability. J Magn Reson Imaging 30(6):1249-1258

52. Ersoy H, Rybicki FJ (2007) Biochemical safety profiles of gadolinium-based extracellular contrast agents and nephrogenic systemic fibrosis. J Magn Reson Imaging 26:1190-1197

53. Morcos SK (2008) Extracellular gadolinium contrast agents : differences in stability. Eur J Radiol 66:175-179

54. Sherry AD, Caravan P, Lenkinski RE (2009) Primer on gadolinium chemistry. J Magn Reson Imaging 30(6):1240-1248

55. Sieber MA, Frenzel T, Siegmund F (2008) Preclinical investigation to compare different gadolinium-based contrast agents regarding their propensity to release gadolinium in vivo and to trigger nephrogenic systemic fibrosis-like lesions. Eur Radiol 18:2164-2173

56. Gibby WA (2004) Comparison of Gd DTPA-BMA (Omniscan) versus Gd HP-DO3A (ProHance) retention in human bone tissue by inductively coupled plasma atomic emission spectroscopy. Invest Radiol 39(3):138-142

57. Shellock FG, Spinazzi A (2008) MRI safety update 2008: part 1, MRI contrast agents and nephrogenic systemic fibrosis. Am J Roentgenol 191(4):1129-1139

58. Elmholdt TR, Pedersen M, Jørgensen B, Søndergaard K, Jensen JD, Ramsing M, Olesen AB (2011) Nephrogenic systemic fibrosis is found only among gadolinium-exposed patients with renal insufficiency: a case-control study from Denmark. Br J Dermatol 165(4):828-836

59. Abujudeh HH, Rolls H, Kaewlai R, Agarwal S, Gebreananya ZA, Saini S, Schaefer PW, Kay J (2009) Retrospective assessment of prevalence of nephrogenic systemic fibrosis (NSF) after implementation of a new guideline for the use of gadobenate dimeglumine as a sole contrast agent for magnetic resonance examination in renally impaired patients. J Magn Reson Imaging 30(6):1335-1340

60. Reiter T, Ritter O, Prince MR, Nordbeck P, Wanner C, Nagel E, Bauer WR (2012) Minimizing risk of nephrogenic systemic fibrosis in cardiovascular magnetic resonance. J Cardiovasc Magn Reson 14(1):31

61. Thomsen HS (2009) How to avoid nephrogenic systemic fibrosis: current guidelines in Europe and the United States. Rad Clin N Am 47(5):871-875

62. Abdel-kader K, Patel PR, Kallen AJ, Sinkowitz-cochran RL, Bolton WK, Unruh ML (2010) Nephrogenic systemic fibrosis: a survey of nephrologists' perceptions and practices. Clin J Am Soc Nephrol 5: 964-971

63. Alhadad A, Sterner G, Svensson A, Alhadad H, Leander P (2012) Incidence of nephrogenic systemic fibrosis at a large university hospital in Sweden. Scand J Urol Nephrol 46:48-53

64. Rees O, Agarwal SK (2010) Nephrogenic systemic fibrosis: UK survey of the use of gadolinium-based contrast media. Clin Radiol 65:636-641

65. Saitoh T, Hayasaka K, Tanaka Y, Kuno T, Nagura Y (2006) Dialyzability of gadodiamide in hemodialysis patients. Radiat Med 24:445-451

66. Broome DR (2007) Response to "will dialysis prevent the development of nephrogenic systemic fibrosis after gadolinium-based contrast administration?". Am J Roentgenol 189:234-235

67. Rodby RA (2008) Dialytic therapies to prevent nsf following gadolinium exposure in high-risk patients. Sem Dial 21(2):145-149

68. Morcos SK (2007) Nephrogenic systemic fibrosis following the administration of extracellular gadolinium based contrast agents: is the stability of the contrast agent molecule an important factor in the pathogenesis of this condition? Br J Radiol 80(950):73-76

69. Cuffy MC, Singh M, Formica R, Simmons E, Abu Alfa AK, Carlson K, Girardi M, Cowper SE, Kulkarni S (2011) Renal transplantation for nephrogenic systemic fibrosis: a case report and review of the literature. Nephrol Dial Transplant 26(3):1099-1101

70. Linfert DR, Schell JO, Fine DM (2008) Treatment of nephrogenic systemic fibrosis: limited options but hope for the future. Semin Dial 21(2):155-159

71. Gilliet M, Cozzio A, Burg G, Nestle FO (2005) Successful treatment of three cases of nephrogenic fibrosing dermopathy with extracorporeal photophoresis. Br J Dermatol 152(3):531-536

72. Mathur K, Morris S, Deighan C, Green R, Douglas KW (2008) Extracorporeal photophoresis improves nephrogenic fibrosing dermopathy/nephrogenic systemic fibrosis: three case reports and review of the literature. J Clin Apher 23(4):144-150

73. Zwerner J, Kim Y, Fiorentino D (2007) Nephrogenic systemic fibrosis: relationship to gadolinium and response to photophoresis. Arch Dermatol 143(8):1025-1030

74. Kadiyala D, Roer DA, Perazella MA (2009) Nephrogenic systemic fibrosis associated with gadoversetamide exposure: treatment with sodium thiosulfate. Am J Kidney Dis 53(1):133-137

75. Swaminathan S, Arbiser JL, Hiatt KM (2010) Rapid improvement of nephrogenic systemic fibrosis with rapamycin therapy: possible role of phopho-70-ribosomal-S6 kinase. J Am Acad Dermatol 62:343345

76. Kay J, High WA (2008) Imatinib mesylate treatment of nephrogenic systemic fibrosis. Arthritis Rheum 58:2543-2548

77. Pieringer H, Schmekal B, Janko O, Biesenbach G (2007) Treatment with corticosteroids does not seem to benefit nephrogenic systemic fibrosis. Nephrol Dial Transplant 22:3094

78. Chung HJ, Chung KY (2004) Nephrogenic fibrosing dermopathy: response to high-dose intravenous immunoglobulin [letter]. Br J Dermatol 150(3):596-597

79. Baron PW, Cantos K, Hillebrand DJ HKQ, Ojogho ON, NehlsenCannarella S, Concepcion W (2003) Nephrogenic fibrosing dermopathy after liver transplantation successfully treated with plasmapharesis. Amer J Dermopathol 25(3):204-209

80. Penfield JG (2008) Nephrogenic systemic fibrosis and the use of gadolinium- based contrast agents. Paediatr Nephrol 21:21212129 
81. Drukker A, Guignard JP (2002) Renal aspects of the term and preterm infant: a selective update. Current Opin Pediatr 14(2):175182

82. Delanghe JR (2009) How to estimate GFR in children. Nephrol Dial Transplant 24(3):714-716

83. Meng H, Grosse-Wortmann L (2012) Gadolinium in pediatric cardiovascular magnetic resonance: what we know and how we practice. J Cardiovasc Magn Reson 14(1):56

84. Boer DP, de Rijke YB, Hop WC, Cransberg K, Dorresteijn EM (2010) Reference values for serum creatinine in children younger than 1 year of age. Pediatr Nephrol 25(10):2107-2113

85. Juluru K, Vogel-Klaussen J, Macura KJ, Kamel IR, Steever A, Bluemke DA (2009) MR imaging in patients at risk for developing nephrogenic systemic fibrosis: protocols, practices, and imaging techniques to maximize patient safety. Radiographics 29(1): 9-22

86. Dawson P, Punwani S (2008) Nephrogenic systemic fibrosis: nongadolinium options for the imaging of CKD/ ESRD patients. Semin Dial 21(2):160-165

87. Zhang HL, Sos TA, Winchester PA, Gao J, Prince MR (2009) Renal artery stenosis: imaging options, pitfalls, and concerns. Prog Cardiovasc Dis 52(3):209-219

88. Campos ROP, Heredia V, Ramalho M, Toni MS, Lugo-somolinos A, Fuller ER, Semelka RC (2011) Quarter dose gadobenate dimeglumine for abdominal mri in patients at risk of nephrogenic systemic fibrosis: preliminary observations. Am J Roentgenol 196: 545-552

89. Nael K, Moriarty JM, Fin JP (2011) Low dose contrast-enhanced mangetic resonance angiography. Eur J Radiol 80(1):2-8

\section{Answers}

1. Correct answer is (a). The others are false: (b) iodinated contrast is more likely to cause transient nephropathy in patients with preexisting renal impairment; (c) hemodialysis removes Gd from the intravascular compartment, but there is scant evidence that this decreases risk of NSF; (d) these are the features of lead poisoning; (e) false

2. Correct answer is (c) Clinical features often occur after a delay, ranging from a few days to 3 years following exposure. The other statements are all true.

3. Correct answer is (e). The others are false: (a) $5 \%$ have rapidly progressive course; (b) $48 \%$ mortality rate over 48 months in hemodialysis patients with features of NSF compared with $20 \%$ in patients without cutaneous disease; (c) approximately $10 \%$ are wheelchair bound; (d) just more than 400 biopsy-proven cases have been reported in the literature.

4. Correct answer is (b). The others are all false: (a) scant evidence to suggest that the risks from Gd are mitigated by dialysis; (c) EMA guidelines suggest medium- and low-risk Gd agents can be used at lowest possible dose, with a 7-day pause between scans; (d) advised to discard milk for $24 \mathrm{~h}$ following high-risk agents; risk-benefit analysis for lowerrisk agents; (e) only five new cases (all adults) have been recorded at the Yale NSF registry since 2009 (personal communication, Yale NSF registry)

5. Correct answer is (d). The others are all false: (a) only ten biopsyproven cases in children at the Yale Registry (all $>6$ years); (b) it is possible to risk profile patients to determine those that require serum creatinine measurement and/or routinely use lower risk agents; (c) noncontrast, e.g., time of flight, MRA techniques are effective; (e) always assess each case on its merits. 